\title{
Low transmission areas of schistosomiasis in Venezuela: consequences on the diagnosis, treatment, and control
}

\author{
Belkisyolé Alarcón de Noya/ ${ }^{+}$, Raiza Ruiz-Guevara, Cecilia Colmenares, \\ Sandra Losada*, Oscar Noya
}

Cátedra de Parasitología, Escuela "Luís Razetti” *Sección de Biohelmintiasis, Instituto de Medicina Tropical, Universidad Central de Venezuela, Los Chaguaramos, Apartado Postal 47706, Caracas 1041-A, Venezuela

Schistosomiasis low transmission areas as Venezuela, can be defined as those where the vector exists, the prevalence of active cases is under $25 \%$, individuals with mild intensity of infection predominate and are mostly asymptomatic. These areas are the consequence of effective control programs, however, "silent" epidemiological places are difficult to trace, avoiding the opportune diagnosis and treatment of infected persons. Clinic and abdominal ultrasound have not shown to discriminate infected from uninfected persons in areas where besides Schistosoma mansoni, intestinal parasites are the rule. Under these conditions, serology remains as a very valuable diagnostic tool, since it gives a closer approximation to the true prevalence. In this sense, circumoval precipitin test, ELISA-SEA with sodium metaperiodate, and alkaline phosphatase immunoassay joined to coprology allow the identification of the "schistosomiasis cases". In relation to public health, schistosomiasis has been underestimated by the sanitary authorities and the investment on its control is being transferred to other diseases of major social and political relevance neglecting sanitary efforts and allowing growth of snail population. Some strategies of diagnosis and control should be done before schistosomiasis reemergence occurs in low transmission areas.

Key words: low transmission area - diagnosis - schistosomiasis - Venezuela

As a consequence of effective control programs based on chemical molluscicides, massive or selective chemotherapy and sanitary measures, the prevalence of human schistosomiasis have diminished considerably in American and Asian endemic areas. That has not been the situation in sub-Saharan Africa where prevalence and morbidity due to schistosomiasis is high (WHO 2001).

A complete review of the current situation of those countries where schistosomiasis prevalence has decreased was carried out in Geneva in 2000 (WHO 2001). Thus, Japan, Iran, Montserrat, Puerto Rico, Guadeloupe, Martinique, Saint Lucia, and Venezuela are countries which have with different levels, efficient control measures, while, Brazil, Dominican Republic, China, Laos, Morocco, Egypt, and Saudi Arabia, also with different prevalences rates, could be considered areas of transition. In this sense, to move from a morbidity control to transmission control concept, a consensus on the definition of low transmission areas (LTA) of schistosomiasis must be approached in order to decide the strategy and guidelines for their control. The World Health Organization (WHO) requires a clear definition of LTA as well as the definition of clinical case in a low endemic area of schistosomiasis (WHO 2001).

Financial support: Fonacit project 2000001878

${ }^{+}$Corresponding author: belkisyole@yahoo.com.mx

Received 25 May 2006

Accepted 26 June 2006
Impact of control measures on prevalence in endemic areas of Brazil and Venezuela

Measures based on the snail control have largely applied throughout the world, however the availability of effective drugs against human schistosomiasis have driven to prevalence reduction in some endemic countries (Chistulo et al. 2000). Improvement of sanitary condition is the desirable integral control measure to be applied not only for schistosomiasis but for intestinal parasites also, as it has happened in Puerto Rico and Japan. In the last two decades, in America, although some new foci of schistosomiasis have appeared (WHO 2001), general prevalence has diminished. High prevalence accompanied of abundance of Schistosoma mansoni eggs in the stools have been changed to low prevalence based on coprological results. This is the case of Brazil, where several follow-up studies on the same areas demonstrated significant decrease of the figures, shifting to prevalence under $25 \%$ as shown in Table I. Due to low intensity of infection and the consequent difficulty for the detection of the disease based only in the finding of S. mansoni eggs, serology has been used since 1985 in Venezuela. Table II shows coprological and serological monitoring of communities which reveal that prevalence has diminished considerably. Most of the Venezuelan works included quantitative results of the Kato-Katz in which the average of eggs per gram of feces is always less than 100 . Probably the application of a standard methodology of schistosomiasis communities approach should be necessary in order to well compare the different $S$. mansoni endemic areas in America and to evaluate the impact of any control measure. Such a case was the community of Belén, in Venezuela, where the same methodologies were applied in a group of infected persons to know the ef- 

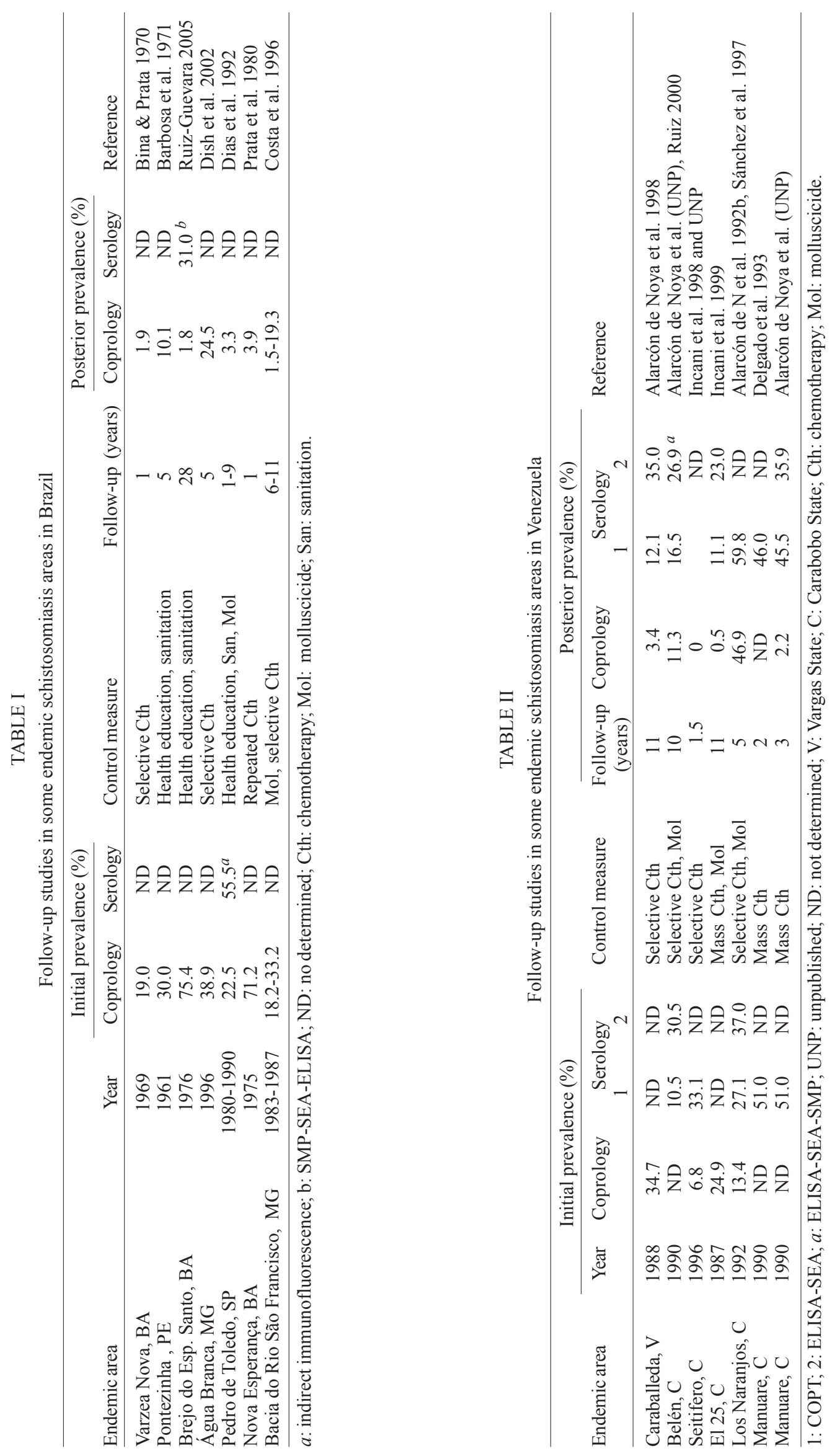
fectiveness of praziquantel five years after treatment (Alarcón de Noya et al. 2004). Table III shows the comparative results of diagnosis tests before and after chemotherapy in Belén where interruption of the transmission was not guaranteed. Although ELISA-SEA with sodium metaperiodate (ELISA-SEA-SMP) and the alkaline phosphatase immunoassay (APIA) are sensible, specific and ideal for mass diagnosis, they do not evaluate cure at least until five years after chemotherapy. The circumoval precipitin test (COPT) and Kato-Katz were the techniques that showed reduction and they remain to be replaced by mass cure diagnosis tests which allow evaluation of the impact of control measures.

\section{Schistosomiasis applied diagnosis in Venezuela}

The schistosomiasis diagnosis and control are unsolved problems in countries as Venezuela, in which approximately $80 \%$ of infected individuals harbor light infections (elimination of $<100$ eggs/g of feces), mostly asymptomatic or with mild morbidity, becoming difficult their detection. Under these conditions, it is a challenge to demonstrate the $S$. mansoni presence since parasitological methods loose their sensitivity. In this context, relatively easy immunologic techniques have been introduced into the Schistosomiasis Control Programme for searching cases (Alarcón de Noya et al. 1992c).

Traditionally, schistosomiasis prevalences were based on stool examination. A great contribution of coprology has been that after the Kato-Katz technique (Katz et al. 1972), the intensity of infection became an obligatory parameter to be explored in field studies. In the last two decades, most of the studies done in Venezuela have reported low intensity of infection (Delgado et al. 1993, Salas et al. 1997, Alarcón de Noya et al. 2002). In our field works, when possible, we took two feces samples with three smears from each one. In more recent studies and due to troublesome of the procedure and the numerous persons to be evaluated, only one sample was taken and two smears of that sample were examined by Kato-Katz. Although the examination of more samples of feces increase the probability of schistosomiasis diagnosis, the quantitative reproducibility of the Kato-Katz method has shown variations, especially when the amount of $S$. mansoni eggs is low (Kong et al. 2001). Teesdale et al. (1985) and Engels et al. (1996) judge that due to the daily variation of the number of eggs, the analysis with two smears would be enough in order to increase the sensibility of the method. Teesdale et al. (1985) found that only $6 \%$ of positive samples were identified after a second exam accomplished in different days, suggesting that for epidemiological purposes, the effort and logistics to obtain two samples of a same person are not worthwhile.

The COPT is the gold standard test in immunodiagnosis of schistosomiasis. This technique usually is carried out according to Spencer et al. (1991). The COPT, in spite of its high sensitivity and specificity, and its correlation with oviposition, remains only as a confirmatory diagnostic test, because it is very laborious and depends on ongoing life cycle (Noya et al. 2002). COPT value decreases slowly after treatment, becoming negative from six months to one year after effective chemotherapy (Alarcón de Noya et al. 1992a).

ELISA is preferred for mass diagnosis. This assay fulfils the requirements of low cost, reproducibility, objectivity and rapid results. ELISA with crude antigens of $S$. mansoni overestimates the prevalence of schistosomiasis infection since it does not discriminate between active and past infections and because false positives are present due to cross-reactivity with other parasites as hookworms (Correa-Oliveira et al. 1988). To overcome this situation, we introduced a modification to reduce false positives treating the antigen with sodium metaperiodate (Alarcón de Noya et al. 2000). Specificity of ELISA-SEA-SMP improves from 73 to $97 \%$, reducing the number of false positive, and maintains a sensitivity of 99\% (Alarcón de Noya et al. 2000).

APIA is an antibody detection technique which permits the diagnosis of schistosomiasis using a butanolic extract preparation from adult worms (Pujol \& Cesari 1990). APIA has demonstrated high sensitivity and specificity (Alarcón de Noya et al. 1997), but it is not being able to confirm active infections. It can remain positive while other tests are negative during unisexual infections, probably a more common condition in areas of low transmission (Alarcón de Noya et al. 1997). This technique can be applied as an initial screening test as ELISA-SEA-SMP.

We have studied the correlation among these tests and at this point we can simplify the algorithm of work. For field work, the whole population can be screened though ELISA-SEA-SMP or APIA. Then, Kato-Katz, and COPT would be applied only to the positives as proposed by Noya et al. (2002). An exam with the advantages of the ELISA-like test that discriminates active from past infection would be very useful when evaluation of the impact of treatment is the goal.

TABLE III

Monitoring of diagnostic tests in 74 schistosomiasis "cases" before and after praziquantel treatment, Belén, Venezuela ${ }^{a}$

\begin{tabular}{cccccc}
\hline & & \multicolumn{3}{c}{ Diagnostic tests for schistosomiasis } \\
\cline { 2 - 6 } Year & ELISA-SEA-SMP & APIA & COPT & \multicolumn{2}{c}{ S. mansoni eggs in feces } \\
\cline { 5 - 7 } 1998 & $\mathrm{n}=74$ & $\mathrm{n}=72$ and 74 & $\mathrm{n}=74$ & $\mathrm{n}=69$ and 72 & Mean egg output \\
2003 & $74(100 \%)$ & $65(90.3 \%)$ & $69(93.2 \%)$ & $45(65.2 \%)$ & 129.8 \\
\hline
\end{tabular}

$a$ : modified from Alarcón de Noya et al. 2004. 


\section{Schistosomiasis case definition}

After several field studies applying coprological and serological techniques and the subsequent evaluation of the epidemiological situation of the Venezuelan foci, we have no doubts that Venezuelan endemic areas studied in the last decades are LTA characterized by low egg output and low morbidity. However, in spite of efficient control programs, schistosomiasis remains as endemic parasitosis and certainly its detection is difficult mainly because people do not feel sick. Therefore the question is: who should be treated? In an area where massive treatment sometimes is not possible, chemotherapy should be given to schistosomiasis cases. There is not agreement in the definition of cases. Based on the fact that morbidity studies in these areas really do not help too much, laboratorial markers of active infection have been taken into consideration to define cases of schistosomiasis. We have proposed three categories (Alarcón de Noya et al. 2002):

Criterion I: persons eliminating eggs of $S$. mansoni in the stools. Generally these persons have positive all serological tests (COPT, ELISA-SEA-SMP, and APIA)

Criterion II: persons with negative stool samples, but positive COPT and other serological tests, who have not received specific treatment in the last year

Criterion III: those persons with negative stools and COPT but positive ELISA-SEA-SMP and APIA, who never have been treated for schistosomiasis.

\section{Clinical characterization of schistosomiasis cases}

Intestinal schistosomiasis morbidity is difficult to evaluate. Unspecific digestive symptoms are shared with others pathogens, especially intestinal parasites, a common condition in endemic areas. In many cases, patients receive symptomatic treatment without investigation of the etiology of the diarrhea process.

Authors as Gryseels (1988) considered the hepatomegaly as the classical hepatic morbidity signs; other investigators attribute more importance to liver characteristics such as hard consistency, the presence of nodules on the hepatic surface, or the prominence of the left lobe (Prata 1970). However, in Venezuela, the finding of palpable liver below the costal margin and data about liver consistency, hepatic surface, and left lobe prominence are neither related to the presence of schistosomiasis or parasitic burden (Ruiz et al. 2002).

All the "schistosomiasis cases" already selected by the criteria discussed above, were classified based on clinical manifestations (modified from Prata 1970): hepatointestinal and hepato-splenic. We add the asymptomatic and the intestinal forms. Actually, results from our field studies show that the majority of schistosomiasis-infected persons $(80 \%)$ result in asymptomatic forms of the disease (Alarcón de Noya et al. unpublished observations). Thus, $S$. mansoni-infected persons do not shown specific symptoms except when the disease advances and patients present hepatosplenic involvement. It is important to mention that ultrasonographical signs were also explored and it was found that this technique under the old WHO classification (Jenkins et al. 1992) was not useful as a morbidity marker (Ruiz et al. 2002). For this rea- sons, we propose first to select cases according to laboratory results and then classify them clinically.

\section{Malacology}

In an endemic area it is important to know if ongoing transmission is taking place. The current presence of snails is a factor to be explored since the hermaphroditic vector of the disease Biomphalaria glabrata, has demonstrated to be very resistant to dryness and is able to repopulate an area in a relative short period of time. On the other hand, the elimination of eggs in stools is sporadic but prolonged, due to parasite longevity. In fact, in a community where transmission was interrupted and chemotherapy was extensively given, with annual visit to the focus without any evidence of snail presence, $3.4 \%$ of the persons continued excreting eggs in their feces 15 years after disappearance of the vector (Alarcón de Noya et al. 1998). The biologic features of the vector and the parasite are factors that can guarantee the re-emergency of transmission in a focus where parameters of low transmission have been determined. Often, transmission is focal and usually few snails get infected, therefore it is probable that some could be exposed to only one miracidium and in consequence unisexual infections might be present. This fact could be responsible for "false positives" detected by serological assays, since, they do not represent a problem in terms of pathology and epidemiology of this infection; by the contrary, these individuals could be more resistant to re-infections, helping to maintain a lower prevalence in these areas. The presence of snails allowed us to better describe the kind of focus we were dealing with (Alarcón de Noya et al. 2002). Low transmission area is not a static concept. Without the adequate surveillance, a LTA can eventually become in higher transmission area. The presence, susceptibility or infection by S. mansoni of the snail vector at the place under study, must be included in the definition of the transmission area.

\section{Low transmission area definition}

Clinical and parasitological features of the human host are taken into account, but some characteristics related to the snail vector should be included also. A proposal for the definition of LTA should include all the following factors: (a) prevalence of schistosomiasis cases in $25 \%$ or less of the examined population; (b) predominance $(75 \%$ or more) of low intensity of infection; (c) low morbidity with predominance of asymptomatics; (d) focal presence of susceptible Biomphalaria spp. snails.

\section{The importance of defining schistosomiasis areas based on their transmission and the consequences on the control and risks of being a schistosomiasis low transmission area}

As consequence of control measures (chemotherapy, sanitation, snail control) transmission decreases. The population of snails can be reduced with the application of molluscicides or biological control. Thus, fewer snails get infected and the production of cercariae significantly diminishes when fewer S. mansoni eggs contaminated the water bodies. As a chain, susceptible hosts are infected with less cercariae and the pathological damage produced 
by $S$. mansoni eggs is less severe. Clinical manifestations are not as dramatic as they used to be and the acute phase of the disease passes unnoticed to the chronic phase. During this period, production of low quantities of eggs continues, these are trapped in the tissue and their presence in the stools is each time less evident (Warren 1978). Clinical diagnosis is the first affected parameter since $S$. mansoni-infected persons do not declare symptoms different from those of the non infected (Ruiz et al. 2002). Moreover, abdominal ultrasound, an excellent non invasive tool, that can detect fibrosis, is not very different among these two groups (Ruiz et al. 2002). Laboratorial diagnosis becomes difficult because stool examination with the useful Kato-Katz technique, looses sensitivity and underestimates the prevalence (Engels et al. 1996, Kong et al. 2001). Serological help has been proposed more than a decade ago in order to overcome this problem and to reach as much as possible the real prevalence (Alarcón de Noya et al. 1992), in spite that immunological tests need blood sample, trained persons and adequate infrastructure. Although antigen detecting techniques (van Lieshout et al. 2000) and detection of DNA parasite particles (Rabello et al. 2002) have not been completely successful in their application in endemic areas, a test detecting parasite presence is needed for massive application in field work, specially when a control measure has to be evaluated.

Low prevalence also means that not all the people at risk, even living close to transmission areas are infected, therefore massive treatment under these conditions can be questionable. In places where cysticercosis overlaps to schistosomiasis ones, massive praziquantel administration can increase the possibility of seizures and be inconvenient for the control program (Torres et al. 1988). The definition of transmission areas has clear implications in treatment application. Chemotherapy rules change in high or low transmission areas. While massive treatment is justified in countries with high intensity of infection or also high morbidity, selective treatment seems to be the adequate measure in LTA. Would it be necessary to monitor the treatment effectiveness to ensure that nobody eliminates eggs and consequently contaminates water supplies? A question arises, should treatment be repeated? How often in LTA? In our hands effectiveness of praziquantel has not been shown to be absolute (Incani et al. 1998). In the past we demonstrated that in a population where the transmission was interrupted, $38 \%$ of the persons controlled one year after praziquantel treatment, continue with active infection (Alarcón de Noya et al. 1992a, García et al. 2006). It seems that at least two years after chemotherapy, a new surveillance must be carried out to additionally minimize the effect of migrating persons out of the endemic area.

Based on this discussion, the aim of the control is different among the areas of high or low transmission. Decrease of morbidity control is the goal of control in high endemic transmission areas and transmission control should be the goal in the low endemic ones, as already has been achieved by WHO (2001). Moreover, the presence of extra human hosts has implications if the area is submitted to an interruption or elimination of transmission (WHO 2001).

\section{Proposal}

As soon as the prevalence diminishes, the epidemiological surveillance decreases. The control programs of metaxenic diseases bypass their financial supports sources to other priorities. This interrupted and weak surveillance allows snail population to grow, aided by their natural resistance to seasonal climatic changes and their hermaphroditic condition. In this way progressive multiplication of snails occur without any control.

Before the reemergence of schistosomiasis turns LTA in high transmission ones, some strategies should be applied to elimination of transmission in those countries where animal reservoirs do not play any role in the transmission chain. For discussion, some recommendations arise: (a) being the American schistosomiasis mainly an antroponotic infection, integral epidemiological surveillance should be emphasized on the human definitive host, remarking sanitary education and communitarian participation as main measure of control; (b) environmental measures joined with biological control of vectors are preferable. The application of chemical molluscicides must be reserved to inaccessible or inadequate areas where biological control can not be applied, or focally where infected snails have been found; (c) it is time for evaluation of the widely used praziquantel. Treatment effectiveness evaluations in foci with different epidemiological features, where interruption of transmission is guaranteed, is needed to know the reliability of the current scheme of treatment; (d) antigen detecting techniques, COPT, or PCR should be the diagnosis tests to be used in follow-up studies to really estimate the impact of control measures; (e) in a well defined schistosomiasis LTA free of animal reservoirs, the goal must be the parasite elimination.

Although we have conscience of the big difference with the Plasmodium model in which Arnoldo Gabaldón worked, we would like to remain his talk about control "En las últimas reuniones de Directores Nacionales de Servicios Antimaláricos de nuestras Repúblicas Latinoamericanas, se ha hecho hincapié que en ellos lo que debe hacerse es el control de la malaria y se deseche la idea de la erradicación. Sorprendentemente, yo estoy de acuerdo con la primera aseveración, pero de ningún modo con la segunda. La primera debe significar sólo la necesidad de detenernos a reflexionar. La segunda tiene un franco sabor a derrota y los verdaderos sanitaristas a quienes de verdad duela su país no lo deben admitir" Guatemala, 19/01/1987.

\section{ACKNOWLEDGEMENTS}

To Professor Renzo Nino Incani who allowed us to includes unpublished information from his field work.

\section{REFERENCES}

Alarcón de Noya B, Balzán C, Colmenares C, Rodríguez C, Spencer L, Rodríguez E, González M, Stojanovic A, Ruiz E, Romero F, Masroua G, Noya O 1992b. Esquistosomiasis en el caserío de Los Naranjos. Carabobo. Acta Cient Venezol 43 (Supl. 1): 201.

Alarcón de Noya B, Cesari IM, Losada S, Colmenares C, Balzán C, Hoebeke J, Noya O 1997. Evaluation of alkaline phosphatase immunoassay and comparison with other diagnos- 
tic methods in areas of low transmission of schistosomiasis Acta Trop 66: 69-78.

Alarcón de Noya B, Colmenares C, Lanz H, Caracciolo MA, Losada, S, Noya O 2000. Schistosoma mansoni: Immunodiagnosis is improved by sodium metaperiodate which reduces cross-reactivity due to glycosylated epitopes of soluble egg antigen. Exp Parasitol 95: 106-112.

Alarcón de Noya B, Losada S, Colmenares C, Ruiz R, Acuña N, Castillo M, Vento R, Noya O 2004. Laboratory follow-up before and after praziquantel treatment in a Venezuelan community with low schistosomiasis transmission. Proceeding of the IX European Multicolloquium of Parasitology (EMOP), Spain p. 18-23.

Alarcón de Noya B, Noya O, Balzán C, Cesari IM 1992c. New approaches for the control and eradication of schistosomiasis in Venezuela. Mem Inst Oswaldo Cruz 87 (Suppl. IV): 227-231.

Alarcón de Noya B, Rojas C, Rodríguez I, Rojas S, Requiz A, Certad G, Bruces AC, Oria F, Maracara C, Wagner C, Noya O 1998. Caraballeda 15 años después de un foco activo de esquistosomiasis: persistencia de infección sin transmisión. Acta Cient Venezol 49 (Supl. 2): 298.

Alarcón de Noya B, Ruiz R, Colmenares C, Losada S, Cesari IM, Toro J, Noya O 2002. Schistosomiasis mansoni in areas of low transmission. Epidemiological characterization of Venezuelan foci. Mem Inst Oswaldo Cruz 97 (Suppl. 1): 5-10.

Alarcón de Noya B, Spencer L, Noya O 1992a. Pre and posttreatment immunodiagnostic evaluation in human schistosomiasis mansoni. Mem Inst Oswaldo Cruz 87(Suppl. IV): 271-276.

Barbosa FS, Pinto R, Souza AO 1971. Control of schistosomiasis mansoni in a small north east Brazilian community. Trans $R$ Soc Trop Med Hyg 65: 206-213.

Bina JC, Prata A 1970. Hycanthone no tratamento da esquistossomose em uma área rural com baixo índice de transmissão da doença. Gaz Med Bahia 70: 127-130.

Chistulo L, Engels D, Montresor A, Savioli L 2000. The global status of schistosomiasis and its control. Acta Trop 77: 4151.

Correa-Oliveira R, Dusse LMS, Viana IRC, Colley DG, Carvalho OS, Gazzinelli G 1988. Human antibody responses against schistosomal antigens. I. Antibodies from patients with Ancylostoma, Ascaris lumbricoides or Schistosoma mansoni infections react with schistosome antigens. Am J Trop Med Hyg 38: 348-355.

Costa MFL, Guerra HL, Pimenta Junior FG, Firmo JOA, Uchoa E 1996. Avaliação do programa de controle da esquistossomose (PCE/PCDEN) em municípios situados na bacia do rio São Francisco, Minas Gerais, Brasil. Rev Bras Med Trop 29: 117-126.

Delgado VS, Lara I, Balzán C, Marquez L, Traviezo L, Boyer E 1993. Esquistosomiasis en el Caserío Juaniquero (Valle de Manuare Edo. Carabobo) dos años más tarde del control con quimioterapia en masa. Acta Cient Venezol 44 (Supl. 1): 260 .

Dias LCS, Marçal Junior O, Glasser CM, Kanamura HY, Hotta LK 1992. Control of schistosomiasis mansoni in a low transmission area. Mem Inst Oswaldo Cruz 87 (Suppl. IV): 233-239.
Disch J, Katz N, Pereira e Silva Y, Viana LG, Orsini Andrade M, Rabello A 2002. Factors associated with Schistosoma mansoni infection 5 years after selective treatment in a low endemic area in Brazil. Acta Trop 81: 133-142.

Engels D, Sinzinkayo E, Gryseels B 1996. Day-to-day egg count fluctuation in Schistosoma mansoni infection and its operational implications. Am J Trop Med Hyg 54: 319-324.

García N, Isturiz G, Aular S, Incani RN 2006. The efficacy of human schistosomiasis treatment may depend on the rate of transmission. Parasitol Res. Published online: January 18. Available from URL: http://www.parasitology. informatik.uni-wuerzburg.de/login/frame.php .

Gryseels B 1988. The morbidity of schistosomiasis mansoni in the Rusizi (Burundi). Trans R Soc Trop Med Hyg 82: 582587.

Incani RN, Aular S, Eblen M, Mendoza L, Ballén D, Cesari I 1999. Mass chemotherapy with praziquantel as a tool for control of schistosomiasis mansoni in a community of low transmission. Acta Cient Venezol 50 (Supl. 2): 341.

Incani RN, Aular SM, García FA, Loaiza IC, Camejo T 1998. La administración de praziquantel a dosis repetidas incrementa la tasa de curación en personas infectadas con Schistosoma mansoni. Acta Cient Venezol 49 (Supl. 2): 309.

Jenkins JM, Hatz C, Cairo Working Group 1992. The use of diagnostic ultrasound in schistosomiasis - Attempts at standardization of methodology. Acta Trop 51: 45-63.

Katz N, Chaves A, Pellegrino J 1972. A simple device for quantitative stool thick-smear technique in schistosomiasis mansoni. Rev Inst Med Trop São Paulo 14: 397-400.

Kong A, Marks G, Verlé P, van der Stuyft P 2001. The unreliability of the Kato-Katz technique limits its usefulness for evaluating S. mansoni infection. Trop Med Int Health 6: 163-169.

Noya O, Alarcón de Noya B, Losada S, Colmenares C, Guzmán C, Lorenzo MA, Bermúdez H 2002. Laboratory diagnosis in areas of low transmission. A review of a line of research. Mem Inst Oswaldo Cruz 97 (Suppl. 1): 167-170.

Prata A 1970. Como caracterizar a forma hepatosplênica da esquistossomose. In II Simpósio sobre Esquistossomose, Salvador, p. 179-184.

Prata A, Bina JA, Barreto JC, Alecrim MG 1980. Attempt to control the schistosomiasis transmission by oxamniquine, in a hyperendemic locality. Rev Inst Med Trop São Paulo 22: $65-72$.

Pujol FH, Cesari IM 1990. Antigenicity of adults Schistosoma mansoni alkaline phosphatase. Parasite Immunol 12: 189198.

Rabello A, Pontes LA, Dias-Neto E 2002. Recent advances in the diagnosis of Schistosoma infection: the detection of parasite DNA. Mem Inst Oswaldo Cruz 97 (Suppl. 1): 171172.

Ruiz R 2000. Esquistosomiasis y Parasitosis Intestinales: Situación Actual en la Región Centro-norte de Venezuela, 1997-1999, Thesis, Universidad Central de Venezuela, Caracas, 174 pp.

Ruiz-Guevara R 2005. Esquistossomose na Área Hiperendêmica de Brejo do Espírito Santo, Bahia, com Seguimento de 29 
Anos, PhD Thesis, Universidade Federal do Triângulo Mineiro, Uberaba, $275 \mathrm{pp}$.

Ruiz R, Candia P, Garassini M, Tombazzi C, Certad G, Bruces AC, Losada S, Colmenares C, Noya O, Alarcón de Noya B 2002. Schistosomiasis mansoni in low transmission areas. Abdominal ultrasound. Mem Inst Oswaldo Cruz 97 (Suppl. 1): $153-160$.

Salas RM, Sánchez IB, Rodríguez R, Aular SM, Loaiza LC, Balzán C, Incani RN 1997. Esquistosomiasis mansoni en el Valle de Los Naranjos, Estado Carabobo, un foco de alta transmisión I. Epidemiología básica. Acta Cient Venezol 48 (Supl. 1): 173.

Sánchez IB, Salas RM, Rodríguez R, Aular SM, Loaiza LC, Balzán C, Incani RN 1997. Esquistosomiasis mansoni en el Valle de Los Naranjos, Estado Carabobo, un foco de alta transmisión II. Morbilidad. Acta Cient Venezol 48 (Supl. 1): 173.

Spencer L, Alarcón de Noya B, Noya O, Masroua O 1991. Análisis comparativo entre la prueba de precipitación circumoval y ELISA con antígenos crudos para el diagnóstico de la esquistosomiasis en Venezuela. GEN 45: 77-83.

Teesdale CH, Fahringer K, Chistulo L 1985. Egg count variation and sensitivity of a thin smear technique for the diagnosis of Schistosoma mansoni. Trans R Soc Trop Med Hyg 79: 369-373.

Torres J, Noya O, Alarcón de Noya B, Mondolfi A 1988. Seizures and praziquantel. A case report. Rev Inst Med Trop São Paulo 30: 433-436.

van Lieshout L, Polderman AM, Deelder AM 2000. Immunodiagnosis of schistosomiasis by determination of circulating antigens CCA and CAA, in particular in individuals with recent or light infections. Acta Trop 77: 69-80.

Warren KS 1978. The pathology, pathobiology and pathogenesis of schistosomiasis. Nature 273: 609-612.

WHO 2001. Report of the informal consultation on schistosomiasis in low transmission areas: control strategies and criteria for elimination. London, 10-13, April 2000. Document WHO/CDS/CPE/SIP/2001.1. Geneva, 51 pp. 
